\title{
Social Media Exploration and Exploitation by Small and Medium Enterprises for Business Continuity
}

\author{
Lakshmi Goel, University of North Florida, USA \\ Janice Donaldson, Florida Small Business Development Center, USA
}

\begin{abstract}
This paper aims to examine social media usage by small and medium enterprises (SMEs) in the context of business continuity. A key concern for businesses in times of disasters, such as the COVID-19 pandemic or hurricanes, is continuity. This is especially true for SMEs that lack the expertise, awareness, and ability to dedicate specific resources to disaster planning and management. SMEs are quick to explore social media for functions such as customer acquisition, perhaps due to greater flexibility and agility than large companies. However, SMEs are constrained by a lack of resources, limiting the extent to which they can exploit social media. The authors collect data from 68 SMEs and analyze the extent to which they explore and exploit social media tools. The findings suggest that the firms fail to exploit their social media presence to leverage long-term strategic benefits, which would be helpful during a disaster. The contribution includes ways to analyze social media exploration and exploitation and suggestions to strategically manage social media use for business continuity.
\end{abstract}

\section{KEYWORDS}

Business Continuity, Disaster Planning, Small and Medium Enterprises, Social Media Exploitation, Social Media Exploration, Social Media Strategy

\section{INTRODUCTION}

Small and Medium Enterprises (SMEs) form the backbone of an economy. In the state of Florida, SMEs account for $98.9 \%$ of businesses and employ more than $40 \%$ of the workforce ${ }^{1}$. Threats to business continuity during disasters, such as the COVID-19 pandemic or hurricanes, including inventory losses, loss of customers, decline in sales, and operational delays, present significant economic danger. Business continuity plans typically include pre-disaster measures, response during a disaster, and post-disaster strategies. Pre- and post-disaster measures include using savings, soft loans, applying for subsidies or grants, or filing insurance. However, during a disaster, a firm is faced with maintaining continuity in business functions. The role of information systems (IS) and technologies (IT) has been increasingly important for business continuity planning (Cerullo and Cerullo, 2004). Amongst the technologies that can aid with business continuity, social media platforms play an increasing role (Fuchs, 2017; Anderson 2020).

Uses of social media extend beyond simply connecting people (Belo et al., 2013). SMEs use social media platforms for business functions such as market research, customer acquisition, marketing, and customer support (Culnan et al., 2010). The past decade has seen a rise in social media use for business, including for SMEs (Smith and Vardiabasis, 2010). While technologies such as social media 
platforms can be viewed as tools that can change, their use in business functions represents core IT capabilities; i.e., what firms uniquely do with the IT platforms. IT capabilities describe the bundle of key IT assets, including IT skills, technologies, and the alignment between IT and business strategy (Henderson and Venkatraman, 1999). IT capabilities can be vital in business continuity, as has been seen in recent natural disasters (Akram et al., 2018).

From a strategic management perspective, IT capabilities are a form of dynamic capabilities, which have evolved from the resource-based view of a firm. Dynamic capabilities, formed through processes of organizational learning, are seen to drive competitive advantage (Kane and Alavi, 2007; Bhatt and Grover, 2005) rather than the possession of resources or assets such as IT. Two key organizational learning processes, exploration and exploitation (March, 1991), have been studied extensively in strategic management, and adapted in the context of IT capabilities. Research clearly distinguishes between exploration or the adoption of IT tools, and post-adoptive exploitation, where users "extend the feature sets of IT applications introduced to enable organizational work systems" (p. 531, Jasperson et al., 2005).

Most users expend minimal effort and use a small proportion of the functionality of which an IT tool is capable of to try and get their work done. When faced with constraints or challenges, they may look for other tools or resort to manual processes. Tools with low switching costs, such as free social media platforms, make it easy for users to explore them. However, the long-term strategic benefits of technologies often come from exploitation (March, 1991). While there has been substantial research concerning the adoption of social media by SMEs, there is little empiric investigation into the extent to which the adoption is exploration or exploitation. This distinction is important because although organic social media may be free, there are direct and indirect costs associated with managing social media channels that require investment from the organizations. As seen in our sample, these investments occur in the form of personal time, human resources, and monetary expenses - all valuable resources for SMEs, but can have strategic implications for business continuity.

We set out to answer the following question in our study: To what extent do SMEs explore versus exploit social media platforms? In addressing this question, we a) suggest indicators of social media exploration and social media exploitation, and b) provide insights for business continuity. Our pool of SMEs come from firms connected to a regional Florida Small Business Development Center (FSBDC). We gathered data regarding the social media usage of 68 firms from our sample through a survey administered online and found evidence of social media exploration and exploitation. Our findings suggest that despite heavy investments in exploration, few firms exploit their social media channels. We suggest ways in which such exploitation can occur and aid in business continuity.

In the following sections, we describe the theoretical and research backgrounds that motivate and support our inquiry. We then present our research methodology employed to address our research question and discuss our findings. Our results indicate interesting patterns that may provide guidelines for social media adoption by small businesses and are worthy of further studies. We identify the limitations of this study and conclude with takeaways for research and practice.

\section{THEORETICAL BACKGROUND}

\section{Strategy and IT Capabilities}

The resource-based view that a firm can gain competitive advantage with an IT tool has been challenged by the dynamic capabilities perspective, which suggests that a firm derives advantages from how IT is used, i.e. it's IT capabilities (Bhatt and Grover, 2005). IT capabilities describe the bundle of key IT assets, including IT skills, technologies, and the alignment between IT and business strategy (Henderson and Venkatraman, 1999). Aligning a firm's IT infrastructure with its strategy can be seen as a form of organizational learning, a dynamic capability well studied in strategic management literature. And, different IT capabilities, such as experience with IT, or the quality of IT infrastructure, 
yield different sources of IT-based competitive advantage. A firm's IT capabilities has been shown to positively influence organizational performance (Bharadwaj, 2000). In particular, two distinct capabilities - the exploration and exploitation - have been identified as important (Nwankpa and Datta, 2017).

\section{Exploration and Exploitation As IT Capabilities}

Originally used to explain how organizations learn, the relationship between the exploration of new possibilities and the exploitation of old certainties (March, 1991) has been well documented. Exploration, whether at the individual or firm level, implies behaviors characterized by experimentation, discovery, and play, while exploitation is characterized by refinement, consistent improvement, and efficiency (He and Wong, 2004). While both are vital for organizational learning, they have different strategic impacts for organizations. The processes of exploration and exploitation have been applied in the context of IT capabilities (Ferraris et al., 2018). In general, exploration is characterized by search, risk-taking, experimentation, and discovery, whereas exploitation is concerned with refinement, efficiency, and execution (March, 1991). In the context of IT use, prior research clearly distinguishes between the adoption of IT tools, and post-adoptive exploitation, where users "extend the feature sets of IT applications introduced to enable organizational work systems" (Jasperson et al., 2005, p. 531). We extend this idea to social media use.

Social media exploration may be characterized by searching for new applications, with effects that may be realized in the future (Kane and Alavi, 2007; March, 1991), whereas social media exploitation concerns applying existing social media platforms for operational efficiency with consumers, suppliers, co-workers, and partners. As such, the exploitation of social media platforms suggests a higher level of learning that can be costly, which may intimidate resource-constrained SMEs. It, nevertheless, forms a critical part of IT capabilities enabling firms to achieve competitive advantages (Kane and Alavi, 2007). Jasperson and his colleagues have echoed a similar view through investigating post-adoptive behavior and advocated leveraging future technology investment and extending current technology features (Jasperson et al., 2005).

Tools with low switching costs, such as free social media platforms, make it easy for users to explore them. It is easy to create and abandon social media accounts. The easy-to-use user interface enables exploration. Most of these platforms provide a business version of the tool, which is usually bundled with functionality to track, analyze and report default or customized metrics, or engage in different ways. The full functionality of the business version may or may not come at a cost. Exploitative use implies in-depth routine use and familiarity with procedures and functionality concerning IT use (Luo and Ling, 2013). While exploration is essential to innovation, it is suggested that long-term benefits in terms of organizational learning and performance are derived from exploitation (March, 1991). The use of IT capabilities can be vital in business continuity, as has been seen in recent natural disasters.

\section{Research Background}

\section{SMEs and Social Media Platforms}

SMEs are a driving force in the American economy. SMEs hire close to 60 million people, $48 \%$ of the workforce in the U.S. (SBA.Gov, 2019). The definition of an SME depends on the size and the industry of the firm. For example, a business in manufacturing with 500 employees or less is classified as an SME. Due to their size, SMEs often face resource constraints that can reduce their willingness to spend on social media. The use of social media tools has created opportunities for SMEs to enhance operational efficiency and effectiveness, reducing costs, and expanding market potentials (Fink and Disterer, 2006). Some social media platforms seem to be more popular than others, and how they create value for SMEs remains an area of growing interest (McCann and Barlow, 2015).

Social media typically refers to a broad category of IT platforms that support user-generated content. The idea that most social media channels are "free" is attractive to SMEs that often face 
Table 1. Types of Social Media Platforms

\begin{tabular}{|l|l|l|}
\hline Platform type & Key characteristics & Examples \\
\hline Microblogs & Short, frequent posts & Twitter, Snapchat, Instagram \\
\hline Blogs & $\begin{array}{l}\text { Posts displayed in reverse chronological order } \\
\text { by author/s }\end{array}$ & Blogger \\
\hline Forums, Discussion Boards & $\begin{array}{l}\text { Topic oriented conversations/threads often } \\
\text { organized hierarchically }\end{array}$ & $\begin{array}{l}\text { Quora, Industry/product specific } \\
\text { forums }\end{array}$ \\
\hline Co-Creation Sites & Crowdsourced content & Yelp, Reddit, Kickstarter, Wikipedia \\
\hline Social Networking Sites & $\begin{array}{l}\text { Profile-centric platform that enables } \\
\text { connections }\end{array}$ & Facebook, LinkedIn, Google+ \\
\hline Location-Based Tools & Location-tagged content & Foursquare, Facebook Check-in \\
\hline Content Communities & Multimedia content often restricted by file type & YouTube, Pinterest, Flickr \\
\hline
\end{tabular}

financial and human resource constraints. As a result, there has been wide- spread adoption of cloud-based social media tools in lieu of, often expensive, enterprise-based communication and collaboration technologies. Different types of social media channels, with examples of specific tools, are provided in Table 1 .

\section{Social Media and Business Continuity}

Business continuity plans typically lay out actions to be taken by a firm before, during, and after a disaster. Typical business functions, such as market research, customer acquisition, marketing, customer service, and support, acquire different levels of importance at different phases. While companies have the time and resources to focus on long-ranging functions such as market research and new customer acquisition prior to, or after a disaster, functions such as customer service and support are vital to retaining market share during a disaster. In a disaster such as the COVID19 pandemic, many SMEs that relied on a physical storefront are forced to move online. In many cases, while physical business operations may not be substituted by virtual ones, businesses need to maintain communication with customers. In the following paragraphs, we discuss the applicability of different social media platforms for different business functions.

Blogs, forums, and discussion boards are channels best suited for market research. Listening to customers from the existing market generates more than seventy percent of business ideas (Bhidé, 2003). For meaningful market research, it is important to pick platforms where customers are frank in the thoughts and opinions they express. Data, in the form of customer opinions and conversations, is collected through monitoring (Branthwaite and Patterson, 2011). Monitoring may be done through the use of automated tools, which are usually expensive, or manually, a time-intensive exercise. Automated tools for tasks such as opinion mining often incorporate artificial intelligence techniques, such as natural language processing (NLP), to simulate human judgment (Maynard et al., 2012). A decision also needs to be made on whether the monitoring will be real-time or batched.

Customer acquisition and marketing can be supported by creating a dialogue (Gallaugher and Ransbotham, 2010) and spreading the message about a product/service through social media. Communication with extant customers and keeping the core customers informed about the firm's products and services enhances customer loyalty, and is critical for retention in the absence of physical channels. Social networking sites and microblogs are channels best suited for customer acquisition and marketing. They allow for rich, two-way communication with potential and existing customers. Research indicates that a conversational form of communication is most effective on social media platforms (Vernuccio, 2014). Such communication requires real-time acknowledgment and response from the firm (Ashley and Tuten, 2015). 
Table 2. Annua/ Revenue of SMEs in Sample

\begin{tabular}{|l|l|}
\hline Anпиаl Revenue & Count \\
\hline Below $\$ 25 K$ & 30 \\
\hline$\$ 25 K-50 K$ & 8 \\
\hline$\$ 50 K-100 K$ & 10 \\
\hline$\$ 100 K-250 K$ & 13 \\
\hline$\$ 250 K-500 K$ & 8 \\
\hline$\$ 500 K-1 M$ & 10 \\
\hline$\$ 1 M-2.5 M$ & 7 \\
\hline$\$ 2.5 M-5 M$ & 3 \\
\hline$\$ 5 M-10 M$ & 3 \\
\hline Over $\$ 10 M$ & 0 \\
\hline Prefer to not report & 9 \\
\hline Total & $\mathbf{1 0 1}$ \\
\hline
\end{tabular}

Customer service is essential for retention and loyalty, which are keys to business survival. Social media platforms such as forums and discussion boards can be used to empower customers to support each other. This works best for companies that have products that require substantial technical support (examples: Amazon store community, Dell Support Forums). Firms that have customer service personnel can communicate with customers on platforms such as social network sites and microblogs to provide support (examples: Bank of America Help on Twitter, Zappos Service on Twitter).

\section{Research Methodology}

\section{Method}

We prepared an online questionnaire to examine social media use by SMEs. The survey was created using the online tool, Qualtrics. Questions on the survey relating to exploration and exploitation of social media tools were validated in a pre-study with a small sample size of 15 owners of small businesses. The study was approved by the Institutional Review Board under the "Exempt" category (IRB\# 669953-1). We requested participation in the survey in an email that was sent out via the regional FSBDC. From a total pool of 956, we received 101 responses. Responses to all questions were voluntary; i.e., participants of the survey could choose whether or not to answer each question. Within our sample of 101 firms, 68 had complete responses for all questions. We discarded the responses with incomplete data points.

\section{Sample}

Our sample was a convenience sample; i.e., we relied on data from the firms that chose to participate in the study and respond to all questions. Table 2 shows the number of businesses and their annual revenue in USD.

Almost $60 \%$ of the SMEs in the sample were in the service industry. Other industries represented included sales, manufacturing, energy, agriculture, banking and finance, and information technology, as shown in Table 3.

Of the firms surveyed, $33 \%$ were over ten years old, $18 \%$ were between 5-10 years old, and the remaining $49 \%$ were between 1-5 years. Forty-nine percent of the firms were structured as limited liability companies (LLC), 18\% were S-corporations, $18 \%$ sole proprietorship, $12 \%$ C-corporations, and the remaining $3 \%$ were partnerships. 
Table 3. Industries Represented in Sample

\begin{tabular}{|l|l|}
\hline Industry & Count \\
\hline Services & 59 \\
\hline Energy & 3 \\
\hline Sales & 6 \\
\hline Manufacturing & 5 \\
\hline Agriculture & 2 \\
\hline Banking \& Finance & 1 \\
\hline Logistics \& Transportation & 0 \\
\hline Information Technology & 3 \\
\hline Other & 22 \\
\hline Total & $\mathbf{1 0 1}$ \\
\hline
\end{tabular}

\section{Analysis and Results}

We asked our sample of SMEs questions regarding social media use. Based on our pilot study, we included questions relating to the exploration and exploitation of social media tools. Evidence of an online presence and the use of resources for social media may indicate exploration. Exploitation, on the other hand, is denoted by the extent to which each tool is used. Indicators, such as the use of social media for specific functions (Baird and Parasnis, 2011), tracking of metrics (Aichner and Jacob, 2015), and investment leveraging social media for unique opportunities, may provide evidence of exploitation. We structure this section based on an analysis of data related to exploration versus exploitation.

\section{Exploration}

Firms may use online tools for a variety of reasons, such as e-commerce on a website. Our data shows that among the 68 firms, 38 of them use online resources extensively, while 27 firms indicate that they are starting to show interest in online resources. Only three firms in our sample do not use online resources at all.

Table 4 indicates that a majority of the firms believed that they were using online resources extensively and exploiting them. We excluded the three firms that did not utilize online resources from our subsequent analyses. Our next questions focused on the use of social media.

Resources Expended For Social Media Use

Table 5 indicates that $21.5 \%$ of the SMEs that had an online presence did not use social media platforms. However, $78.5 \%$ did use social media in some way, indicating a relatively high degree of exploration among our sample. The result is not surprising, as more and more, social media is viewed as integral to e-commerce (Abed et al., 2015). We next asked the firms how much they spent on their social media efforts:

We excluded the 14 firms that did not use social media from this particular analysis. Based on Table 6, over half (55\%) of firms spend money on their presence. Thus, despite being free, over half the firms incurred monetary costs to manage their social media channels.

Besides monetary expenses, the use of social media also requires time. As seen in Table 5, 12 out of 51 (24\%) of the firms that use social media have part-time or full-time personnel to manage their presence. Over 76\% (39 of 51) of the firms' social media platforms are managed by the owner/s, denoting a time commitment. Tables 5 and 6 provide evidence that the SMEs sampled did indeed explore social media platforms and expended resources in doing so. 
Table 4. Use of Online Resources

\begin{tabular}{|l|l|}
\hline How would you categorize your use of online resources - such as the Internet/Web? & Count \\
\hline Answer & 3 \\
\hline We do not use online resources & 27 \\
\hline We are becoming more of an online citizen & 38 \\
\hline We use online resources extensively & $\mathbf{6 8}$ \\
\hline Total & \\
\hline
\end{tabular}

Table 5. Use of Social Media

\begin{tabular}{|l|l|}
\hline How do you manage your company's social media presence? & Count \\
\hline Answer & 14 \\
\hline I don't use social media & 21 \\
\hline I do it myself, when I remember & 18 \\
\hline I do it myself, systematically & 7 \\
\hline There is a part-time social media person & 2 \\
\hline There is a full-time social media person & 3 \\
\hline There is a team that manages social media & $\mathbf{6 5}$ \\
\hline Total & \\
\hline
\end{tabular}

Table 6. Expenditure on Social Media Use

\begin{tabular}{|l|l|}
\hline How тисh do you spend on social media for your company per month? \\
\hline Answer & Count \\
\hline$\$ 0$ & 23 \\
\hline$\$ 0-\$ 100$ & 18 \\
\hline$\$ 100-\$ 500$ & 8 \\
\hline$\$ 500-\$ 1500$ & 2 \\
\hline More than $\$ 1500$ & 0 \\
\hline Total & $\mathbf{5 1}$ \\
\hline
\end{tabular}

\section{Exploitation}

Prior research has suggested that fully exploiting the capabilities of social media may entail using platforms for specific functions, tracking metrics related to social media, and investing in strategic uses of social media. Studies on the use of social media for specific functions have included the use of platforms for market research (c.f. Casteleyn et al., 2009; Patino et al., 2012), communication to reach customers (Schivinski and Dabrowski, 2016), conversational marketing (Hays et al., 2013), and customer support (Culnan et al., 2010). Based on these suggestions in prior literature, we delved deeper into how the firms were using social media platforms. 
We decided to keep the firms that had indicated they did not use social media for the remainder of the analyses. This is because the term social media is often perceived to include a narrower set of technologies than it actually does. Platforms such as blogs, professional forums, and discussion boards, as described in Table 1, are sometimes not readily identified as social media, as compared to social networking sites.

\section{Communication and Audience Reach On Social Media}

A key feature of all social media platforms is the ability to engage a firm's audience in two-way communication. An integral part of "Web 2.0", social media leverage technologies that allow for easy publishing and sharing of user-generated content. Business use of social media differs from the older generation of the Web that was dominated by supplier-generated content (such as static Websites) in that it allows for two-way communication with the firm's audience. We asked our sample of firms the degree to which they encouraged user communication:

Table 7 indicates that 24 firms, i.e., $47 \%$ of those that claimed to use social media, enabled user communication. Hence over half the firms using social media did not facilitate user communication, the cornerstone of social media. Table 7 provides a preliminary hint at a relatively low level of exploitation among firms that use social media.

Table 7. Social Media Communication

\begin{tabular}{|l|l|}
\hline Do you foster and facilitate an online environment for social media users to talk about your products? \\
\hline Yes & 24 \\
\hline No & 41 \\
\hline
\end{tabular}

To further examine the extent of social media use, we asked questions pertaining to the degree of reach of nine social media tools commonly used today: Twitter, Facebook, LinkedIn, Instagram, Snapchat, Google+, Blogs, YouTube, and Pinterest.

Table 8 shows that only a fraction of firms is able to reach their audience on social media platforms; this also indicates low exploitation. Companies that answered "None" did not have either active accounts, dormant accounts, or had no activity on their social media accounts. Table 8 also suggests that of the social media platforms available, Twitter, Facebook, and LinkedIn are most likely to be exploited.

\section{Use of Social Media For Specific Functions}

Despite having an online presence and a presence on social media platforms, firms exploring social media may lack focus on the purpose for which they are using a platform. Extensive users, on the other hand, are more likely to have a clear purpose for using a specific social media platform. We asked our sample of firms the extent to which they used a social media platform for the specific function of market research, conversational marketing, and customer service. The results are presented in the tables below.

It is clear from the tables above that very few firms use a specific platform heavily for a particular purpose, providing further evidence of poor exploitation. More specifically, the results suggest that: 1) Facebook and LinkedIn are extensively used for market research, conversational marketing, and customer support; 2) Google+, Blogs, and YouTube are also favored channels for market research; and 3) Google+, Blogs and Twitter are favored for conversational marketing and customer support. 
Table 8. Social Media Reach

Please tell us about your company's audience on social media: - How many people do you reach?

\begin{tabular}{|l|l|l|l|}
\hline & None & Few & Many \\
\hline Twitter & 38 & 18 & 9 \\
\hline Facebook & 21 & 22 & 22 \\
\hline LinkedIn & 24 & 24 & 17 \\
\hline Instagram & 52 & 10 & 3 \\
\hline Snapchat & 57 & 5 & 3 \\
\hline Google+ & 42 & 14 & 9 \\
\hline Blogs & 42 & 16 & 7 \\
\hline YouTube & 47 & 12 & 6 \\
\hline Pinterest & 52 & 9 & 4 \\
\hline Other & 59 & 4 & 2 \\
\hline
\end{tabular}

Table 9. Social Media Use for Market Research

\begin{tabular}{|c|c|c|c|c|c|}
\hline Question & Do not use it & Use it somewhat & Use it moderately & Use it highly & Use it heavily \\
\hline Twitter & 40 & 14 & 5 & 4 & 2 \\
\hline Facebook & 24 & 13 & 9 & 6 & 13 \\
\hline LinkedIn & 21 & 14 & 21 & 3 & 6 \\
\hline Instagram & 54 & 6 & 4 & 1 & 0 \\
\hline Snapchat & 61 & 3 & 1 & 0 & 0 \\
\hline Google+ & 31 & 13 & 10 & 6 & 5 \\
\hline Blogs & 36 & 12 & 10 & 6 & 1 \\
\hline YouTube & 34 & 12 & 11 & 5 & 3 \\
\hline Pinterest & 51 & 5 & 4 & 4 & 1 \\
\hline Other & 52 & 5 & 5 & 0 & 3 \\
\hline
\end{tabular}

These results support industry trends of the user base on the platforms and the intent of the platforms. For example, the professional networking site LinkedIn is used for all business functions.

What is surprising is the under-exploitation of certain platforms such as YouTube and Pinterest that would be well suited for business functions.

\section{Use of Metrics}

The ultimate goal of investments is to derive returns for the business. While most technological investments do not demonstrate ROI right away, it is important to track whether they do so in the long run. Measuring the impact of investments can help businesses tailor their strategy and invest in the right technologies. 
Table 10. Social Media Use for Conversational Marketing

\begin{tabular}{|l|l|l|l|l|l|}
\hline \multicolumn{6}{|l|}{ How mисh do yоu use the following social media tools to engage with your target audience - i.e. have a dialog ? } \\
\hline Question & Do not use it & Use it somewhat & Use it moderately & Use it highly & Use it heavily \\
\hline Twitter & 39 & 10 & 8 & 4 & 4 \\
\hline Facebook & 21 & 12 & 10 & 7 & 15 \\
\hline LinkedIn & 24 & 12 & 16 & 6 & 7 \\
\hline Instagram & 55 & 5 & 5 & 0 & 0 \\
\hline Snapchat & 61 & 3 & 0 & 4 & 0 \\
\hline Google+ & 41 & 7 & 7 & 6 & 6 \\
\hline Blogs & 39 & 9 & 8 & 1 & 3 \\
\hline YouTube & 47 & 6 & 8 & 1 & 3 \\
\hline Pinterest & 52 & 8 & 3 & 2 & 1 \\
\hline Other & 51 & 5 & 6 & 4 & 1 \\
\hline
\end{tabular}

Table 11. Social Media Use for Customer Support

How much do you use the following social media to support your target audience, e.g., by answering questions about your product or service?

\begin{tabular}{|l|l|l|l|l|l|}
\hline Question & Do not use it & Use it somewhat & Use it moderately & Use it highly & Use it heavily \\
\hline Twitter & 43 & 15 & 3 & 1 & 3 \\
\hline Facebook & 30 & 14 & 2 & 9 & 10 \\
\hline LinkedIn & 33 & 18 & 7 & 5 & 2 \\
\hline Instagram & 57 & 7 & 1 & 0 & 0 \\
\hline Snapchat & 60 & 4 & 0 & 1 & 0 \\
\hline Google+ & 43 & 12 & 4 & 2 & 4 \\
\hline Blogs & 45 & 12 & 5 & 0 & 3 \\
\hline YouTube & 50 & 11 & 2 & 0 & 2 \\
\hline Pinterest & 58 & 6 & 0 & 1 & 0 \\
\hline Other & 56 & 5 & 2 & 1 & 1 \\
\hline
\end{tabular}

Almost all social media platforms supply usage metrics for business accounts. Facebook Insights, Google Analytics, YouTube Analytics, Twitter Analytics, etc., have built-in functionality for users to track standard and, in some cases, customized metrics such as audience reach, engagement, and return-on-investment for paid campaigns. We asked our sample of firms if they measured the impact of social media on revenue in some way.

Of the 51 firms that self-reported the use of social media, only 15 (29\%) measured its impact on revenue. We asked the 15 firms if they had seen an effect of social media on revenue.

Interestingly, all 15 firms that did track metrics to measure the impact of social media experienced an increase in revenue that could be attributed to efforts on social media. The result in Table 13 is promising and bears further investigation. 
Table 12. Social Media's Impact on Revenue

\begin{tabular}{|l|l|}
\hline Do you measure the impact that social media has on revenue? \\
\hline Answer & Count \\
\hline Yes & 15 \\
\hline No & 50 \\
\hline
\end{tabular}

Table 13. Impact of Social Media on Revenue

\begin{tabular}{|l|l|}
\hline How much impact does Social Media have on revenue, annually? \\
\hline Answer & Count \\
\hline$\$ 0-\$ 2,999$ & 6 \\
\hline$\$ 3,000-\$ 5,999$ & 3 \\
\hline$\$ 6,000-\$ 9,999$ & 3 \\
\hline More than $\$ 10,000$ & 3 \\
\hline Total & $\mathbf{1 5}$ \\
\hline
\end{tabular}

Although beyond the scope of this research, the question of ROI on social media efforts is a pertinent one (McCann and Barlow, 2015), and our limited sample shows evidence that it does indeed occur.

\section{Leveraging New Affordances of Social Media}

While market research, marketing, and customer support are existing functions of all organizations, social media can enable companies to exploit new opportunities. Particularly for SMEs, harnessing social collaboration for co-creation of new products and services can provide new avenues for innovation (Piller et al., 2011).

As Table 14 shows, it is uncommon for firms to use social media to garner innovative ideas for products and services.

Based on our results, it was apparent that most SMEs sampled were heavy explorers but not exploiters of social media.

\section{Discussion}

We set out to answer the research question: To what extent do SMEs explore versus exploit social media platforms? While there is evidence in extant research of the significant use of social media by SMEs, the nature of the use is yet unexplored (Wamba and Carter, 2016). As a first step, we analyzed social media use by $68 \mathrm{SMEs}$ through the lens of exploration versus exploitation. We found that the SMEs in our sample were indeed heavy explorers of social media. They also expended resources in terms of time and monetary investments on social media platforms.

Despite the heavy exploration, many in our sample failed to exploit their presence on social media. This may be a missed opportunity, especially in the context of business continuity during disasters. By systematically exploiting social media channels, SMEs may be able to establish reliable crisis communication, share situational awareness updates, maintain a web "storefront," and signal solidarity with the local community. A core feature of social media, one that differentiates it from prior Web technologies, is the ability to engage users in the dialog. Yet, over half the firms in our sample using social media failed to do so. Firms also failed to focus on specific uses for social media. Given the inherent differences in functionality and affordances of various social media platforms, it 
Table 14. Social Media Use for Innovation

\begin{tabular}{|l|l|l|l|}
\hline \multicolumn{4}{|l|}{ How often do you use the following social media to get new ideas for your products/ services from your target audience? } \\
\hline Question & Never & Sometimes & Often \\
\hline Twitter & 59 & 5 & 1 \\
\hline Facebook & 49 & 10 & 6 \\
\hline LinkedIn & 59 & 3 & 3 \\
\hline Instagram & 64 & 1 & 0 \\
\hline Snapchat & 64 & 1 & 0 \\
\hline Google+ & 57 & 7 & 1 \\
\hline Blogs & 63 & 2 & 0 \\
\hline YouTube & 61 & 4 & 0 \\
\hline Pinterest & 63 & 2 & 0 \\
\hline Other & 63 & 2 & 0 \\
\hline
\end{tabular}

is possible to leverage specific platforms for particular business functions. For example, research has shown that YouTube enjoys a large user base and is an excellent platform for firms to provide tutorials and "how-tos" for customer support. Also, being part of the Google family, a presence on YouTube boosts search engine optimization (SEO), an important goal for a company's presence online. Yet, even the firms using YouTube did not leverage the affordance of connecting with the audience via video content for customer support.

Another critical component of technology use is the ability to track its impact on revenue. We found that a majority of the firms using social media did not measure its impact on the firm's revenue. Interestingly, amongst the ones that did, all firms noticed a positive return on investment in social media. Failure to track ROI may cause firms to undervalue their exploration and fail to capitalize on their efforts, or worse, give up because of not seeing results (McCann and Barlow, 2015). Systematically tracking social media impact allows firms to strategize how to best manage their efforts and investments.

Finally, we find that firms predominantly use social media in lieu of other means to carry out existing business functions. Functions such as market research, marketing, and customer support have traditionally been, and may still be, supported by technologies other than social media. Social media affords unique opportunities for businesses to connect with their audience in ways that were not possible earlier (Dahnil et al., 2014) - for example, getting input on new products or services required expensive focus group studies or impersonal surveys. With crowd-sourcing platforms like Kickstarter, companies can leverage the "wisdom of crowds" for early market feedback and buy-in (Zhao and Zhu, 2014). Innovations can also result from suggestions from social media rather than from within a firm's boundaries. Our analysis shows that even among the firms that use social media, a few leverage the unique affordances of social media for innovation.

Our study supports extant research on the heavy use of social media by SMEs. However, we present a more nuanced analysis of the type of use. By not exploiting the use of social media platforms, we believe that SMEs fail to capitalize on the long-term strategic benefits that may be afforded by social media technologies, especially in the context of business continuity.

\section{Limitations and Future Research}

As with any research, our study has certain limitations. Our sample was obtained from a pool of SMEs through an email soliciting participation. Our response rate was approximately $10 \%$. We likely have 
a respondent bias in our sample. The sample size is relatively small, albeit larger than other similar studies of SMEs. In part, this is due to the difficulty in obtaining data from SMEs.

Our data collection is through a cross-sectional survey. Measures of exploitation can be better studied through a longitudinal design.

Given our small sample size, we were restricted in the type of analysis we could conduct. We relied primarily on descriptive statistics. A more robust, random sample would have allowed for further statistical analysis such as regression or analysis of variance. It is possible that our sample is not representative of all SMEs.

Our focus was primarily on the use of social media by SMEs, irrespective of the type of audience. The use of social media will no doubt differ based on audience characteristics, such as businessto-business or business-to-consumer, access to online technologies, comfort with social media, demographics, etc.

The limitations of this study serve as avenues for future research. We hope that other researchers interested in the use of social media by SMEs and we can extend this study in further directions. We would like to extend our survey to reach a broader pool of SMEs and include other indicators of social media exploration and exploitation. Correlation between firm-level factors, such as involvement by senior management, firm size (Verheyden and Goeman, 2013), and operational factors (Harrigan and Miles, 2015) can be studied in relation to social media use. We hope that this study provides the first step for future research.

\section{CONCLUSION}

The adoption and use of technologies are often nuanced. There is substantial evidence of SMEs heavily adopting and using social media platforms. However, the nature of use bears further investigation. There is usually little slack resource in SMEs to cover unexpected expenses. As a result, the budget is carefully planned to cover major business operations. If social media usage is not considered strategic to business operations, it is likely that the SMEs will not invest in social media tools or personnel. Despite several tools that allow for automation, most social media channels rely on novel content generation and real-time interaction by people responsible for maintaining the channels. In SMEs, this task is often borne by the business owner or an employee who is juggling several other job functions. Without strategic planning, the use of social media can be hampered in disruptive times when business continuity is especially important.

To our knowledge, no research has addressed the phenomenon of social media exploration versus exploitation. In fact, empirical examination of social media usage in the business context, and particularly by SMEs, is scarce. To address this gap in research, we conducted a survey of social media exploration and exploitation by over 100 SMEs. Our overarching research question was: To what extent do SMEs explore versus exploit social media platforms?

Results from our study show that a majority of SMEs with an online presence does indeed use social media platforms. However, we show that the use of social media is limited to exploration. Despite the investment of time and monetary resources, most SMEs fail to exploit their presence on social media channels. By using social media for maintaining communication and reach, supporting specific business functions, tracking metrics, and discovering innovative business practices, firms can incorporate social media in their business continuity plans. In this study, we identify ways to analyze exploration and exploitation and offer researchers and SMEs tools to make the most of their presence on social media platforms. 


\section{REFERENCES}

Abed, S. S., Dwivedi, Y. K., \& Williams, M. D. (2015). Social media as a bridge to e-commerce adoption in SMEs: A systematic literature review. The Marketing Review, 15(1), 39-57. doi:10.1362/146934715X14267608178686

Aichner, T., \& Jacob, F. (2015). Measuring the degree of corporate social media use. International Journal of Market Research, 57(2), 257-276. doi:10.2501/IJMR-2015-018

Akram, M. S., Goraya, M., Malik, A., \& Aljarallah, A. M. (2018). Organizational performance and sustainability: Exploring the roles of IT capabilities and knowledge management capabilities. Sustainability, 10(10), 3816. doi:10.3390/su10103816

Anderson, K. A. (2020). Utilising social media within incident response programmes. Journal of Business Continuity \& Emergency Planning, 14(2), 136-141. PMID:33239145

Ashley, C., \& Tuten, T. (2015). Creative strategies in social media marketing: An exploratory study of branded social content and consumer engagement. Psychology and Marketing, 32(1), 15-27. doi:10.1002/mar.20761

Baird, C. H., \& Parasnis, G. (2011). From social media to Social CRM: Reinventing the customer relationship. Strategy and Leadership.

Belo, A., Castela, G., \& Fernandes, S. (2013). How Small and Medium Enterprises Are Using Social Networks? Evidence from the Algarve Region. Advances in Information Systems and Technologies, 206, 143-155. doi:10.1007/978-3-642-36981-0_14

Bharadwaj, A. S. (2000). A resource-based perspective on information technology capability and firm performance: An empirical investigation. Management Information Systems Quarterly, 24(1), 169-196. doi:10.2307/3250983

Bhatt, G. D., \& Grover, V. (2005). Types of Information Technology Capabilities and Their Role in Competitive Advantage: An Empirical Study. Journal of Management Information Systems, 22(2), 253-277. doi:10.1080/ 07421222.2005 .11045844

Bhidé, A. V. (2003). The origin and evolution of new businesses. Oxford University Press.

Branthwaite, A., \& Patterson, S. (2011). The power of qualitative research in the era of social media. Qualitative Market Research, 14(4), 430-440. doi:10.1108/13522751111163245

Casteleyn, J., Mottart, A., \& Rutten, K. (2009). How to use data from Facebook in your market research. International Journal of Market Research, 51(4), 439-447. doi:10.2501/S1470785309200669

Cerullo, V., \& Cerullo, M. J. (2004). Business continuity planning: A comprehensive approach. Information Systems Management, 21(3), 70-78. doi:10.1201/1078/44432.21.3.20040601/82480.11

Culnan, M. J., McHugh, P. J., \& Zubillaga, J. I. (2010). How large US companies can use Twitter and other social media to gain business value. MIS Quarterly Executive, 9(4).

Dahnil, M. I., Marzuki, K. M., Langgat, J., \& Fabeil, N. F. (2014). Factors influencing SMEs adoption of social media marketing. Procedia: Social and Behavioral Sciences, 148, 119-126. doi:10.1016/j.sbspro.2014.07.025

Ferraris, A., Monge, F., \& Mueller, J. (2018). Ambidextrous IT capabilities and business process performance: An empirical analysis. Business Process Management Journal, 24(5), 1077-1090. doi:10.1108/BPMJ-07-2017-0201

Fink, D., \& Disterer, G. (2006). International case studies: To what extent is ICT infused into the oper-ations of SMEs? Journal of Enterprise Information Management, 19(6), 608-624. doi:10.1108/17410390610708490

Fuchs, C. (2017). Social media: A critical introduction. Sage (Atlanta, Ga.).

Gallaugher, J., \& Ransbotham, S. (2010). Social media and customer dialog management at Starbucks. MIS Quarterly Executive, 9(4).

Goel, L., Blackwood, G., \& Person, K. (2014). Social media in small and medium enterprises. Journal of Digital \& Social Media Marketing, 2(2), 176-184.

Harrigan, P., \& Miles, M. (2014). From e-CRM to s-CRM. Critical factors underpinning the social CRM activities of SMEs. Small Enterprise Research, 21(1), 99-116. doi:10.1080/13215906.2014.11082079 
Hays, S., Page, S. J., \& Buhalis, D. (2013). Social media as a destination marketing tool: Its use by national tourism organisations. Current Issues in Tourism, 16(3), 211-239. doi:10.1080/13683500.2012.662215

He, Z. L., \& Wong, P. K. (2004). Exploration vs. exploitation: An empirical test of the ambidexterity hypothesis. Organization Science, 15(4), 481-494. doi:10.1287/orsc.1040.0078

Henderson, J. C., \& Venkatraman, H. (1999). Strategic alignment: Leveraging information technology for transforming organizations. IBM Systems Journal, 38(2.3), 472-484.

Kane, G. C., \& Alavi, M. (2007). Information technology and organizational learning: An investigation of exploration and exploitation processes. Organization Science, 18(5), 796-812. doi:10.1287/orsc.1070.0286

Luo, Y., \& Ling, H. (2013). Exploration and Exploitation of Information Systems Usage and Individual Performance. Procedia Computer Science, 22, 863-872. doi:10.1016/j.procs.2013.09.169

March, J. G. (1991). Exploration and exploitation in organizational learning. Organization Science, 2(1), 71-87. doi:10.1287/orsc.2.1.71

Maynard, D., Bontcheva, K., \& Rout, D. (2012). Challenges in developing opinion mining tools for social media. Proceedings of the@NLP can u tag\# usergeneratedcontent, 15-22.

McCann, M., \& Barlow, A. (2015). Use and measurement of social media for SMEs. Journal of Small Business and Enterprise Development, 22(2), 273-287. doi:10.1108/JSBED-08-2012-0096

Nwankpa, J. K., \& Datta, P. (2017). Balancing exploration and exploitation of IT resources: The influence of Digital Business Intensity on perceived organizational performance. European Journal of Information Systems, 26(5), 469-488. doi:10.1057/s41303-017-0049-y

Patino, A., Pitta, D. A., \& Quinones, R. (2012). Social media's emerging importance in market research. Journal of Consumer Marketing, 29(3), 233-237. doi:10.1108/07363761211221800

Peters, K., Chen, Y., Kaplan, A. M., Ognibeni, B., \& Pauwels, K. (2013). Social media metrics-A framework and guidelines for managing social media. Journal of Interactive Marketing, 27(4), 281-298. doi:10.1016/j. intmar.2013.09.007

Piller, F. T., Vossen, A., \& Ihl, C. (2011). From social media to social product development: the impact of social media on co-creation of innovation. https://advocacy.sba.gov/2019/04/24/2019-small-business-profiles-for-thestates-and-territories/

Schivinski, B., \& Dabrowski, D. (2016). The effect of social media communication on consumer perceptions of brands. Journal of Marketing Communications, 22(2), 189-214. doi:10.1080/13527266.2013.871323

Smith, W. R., \& Vardiabasis, D. (2010). Using social media as a competitive advantage: The case of small businesses. Problems and Perspectives in Management, 8(4), 193-197.

Verheyden, M., \& Goeman, K. (2013). Does (company) size matter? Differences in social media usage for business purposes. Journal of Applied Quantitative Methods, 8(4).

Vernuccio, M. (2014). Communicating corporate brands through social media: An exploratory study. International Journal of Business Communication, 51(3), 211-233. doi:10.1177/2329488414525400

Wamba, S. F., \& Carter, L. (2016). Social media tools adoption and use by SMES: An empirical study. In Social Media and Networking: Concepts, Methodologies, Tools, and Applications (pp. 791-806). IGI Global.

Zhao, Y., \& Zhu, Q. (2014). Evaluation on crowdsourcing research: Current status and future direction. Information Systems Frontiers, 16(3), 417-434. doi:10.1007/s10796-012-9350-4

\section{ENDNOTE}

1 https://www.sba.gov/sites/default/files/advocacy/Florida.pdf 